\title{
From soil to soil-less in horticulture: quality and typicity
}

\author{
Rosario Di Lorenzo, ${ }^{1}$ Antonino Pisciotta, ${ }^{1}$ Pietro Santamaria, ${ }^{2}$ Valentina Scariot ${ }^{3}$ \\ ${ }^{1}$ Dipartimento Scienze Agrarie e Forestali, Università di Palermo; \\ ${ }^{2}$ Dipartimento di Scienze Agro-Ambientali e Territoriali, Università di Bari; \\ ${ }^{3}$ Dipartimento di Scienze Agrarie, Forestali e Ambientali, Università di Torino, Italy
}

\begin{abstract}
In this review, the technique of soil-less cultivation of horticultural crops is analysed, the main differences between this and traditional cultivation techniques are described, and the advantages and disadvantages of each method in relation to the others are identified. Soilless cultivation has revolutionised various sectors of vegetable and floriculture production, and recent years have also seen interest being shown by Italian fruit crop producers, particularly those involved in table grape viticulture. The various issues related to the use of this technique are described in relation to the needs of the substrate, water management, and mineral nutrition of the different species, and to the fact that not all species are suitable for the application of soil-less cultivation. Finally, since the soil-less system is strongly influenced by Man and is increasingly conditioned by this, the links between the final product and the territory where it is grown appear to be very limited. This is particularly true in Italy where, for certain protected geographical indication food products, soil-less cultivation is prohibited.
\end{abstract}

\section{Introduction}

In horticultural crop production, the definition soil-less cultivation encompasses all the systems that provide plant management in soilless conditions in which the supply of water and of minerals is carried out by nutrient solution, with or without a growing medium (e.g. rockwool, peat, perlite, pumice, coconut fibre, etc.). Soil-less cultivation

Correspondence: Rosario Di Lorenzo, Dipartimento Scienze Agrarie e Forestali, Università di Palermo, viale delle Scienze Ed.,4 90128, Palermo, Italy. E-mail: rosario.dilorenzo@unipa.it

Key words: substrate, nutrient solution, vegetables, floriculture, table grape.

Conference presentation: AISSA Palermo, 2012. Represented society at AISSA: Società di Ortoflorofrutticoltura Italiana.

Received for publication: 25 June 2013.

Revision received: 14 October 2013.

Accepted for publication: 14 October 2013.

(C) Copyright R. Di Lorenzo et al., 2013

Licensee PAGEPress, Italy

Italian Journal of Agronomy 2013; 8:e30

doi:10.4081/ija.2013.e30

This article is distributed under the terms of the Creative Commons Attribution Noncommercial License (by-nc 3.0) which permits any noncommercial use, distribution, and reproduction in any medium, provided the original author(s) and source are credited. systems can be divided into: i) systems in the liquid medium, which do not have other media for the support of plant roots; and ii) systems in the solid medium, using a substrate to support the plants. The hydroponic system is made up of the systems in liquid medium and systems that use an inert substrate. In addition, the soil-less substrate cultures are classified into: i) open systems (when the nutrient solution that drains from the roots is not reused); and ii) closed systems (when the surplus nutrient solution is collected, corrected and put back into the system) (Winsor and Schwarz, 1990).

The soil-less crops are mainly grown in the greenhouse and require high technology, considerable capital investment, and adequate professional skills on the part of the operator. Nevertheless, they are highly productive and ergonomic, they use water and space efficiently, and, in closed loop systems, prevent the pollution of soil and groundwater (Resh, 2012).

The soil-less cultivation systems have been introduced in protected crops in order to: i) release the cultivation of plants from soil and, therefore, from all the problems related to it, such as the phenomena of soil exhaustion, soil-borne diseases (especially after the ban on the use of methyl bromide as a geo-insecticide), secondary salinisation caused by the excessive input of fertilisers and lack of rainfall, the necessity of implementing crop rotation; ii) improve the control of plant growth conditions (e.g. temperature and aeration of the root zone, optimal distribution of water and nutrients, etc.); iii) reduce the amount of labour needed.

Compared to traditional soil cultivation, soil-less crops have many advantages and disadvantages (Table 1). The elements that differentiate soil-less cultivation from traditional techniques mainly concern the use of the nutrient solution and the absence of soil (which may be substituted, in some of its functions, by the substrate).

\section{The nutrient solution}

All soil-less cultivation systems, with or without substrate, have something in common: the distribution of essential nutrients (except carbon) by using a nutrient solution (La Malfa, 1996).

The principles of mineral nutrition of plants grown without soil are no different from those of plants grown on soil. The main difference between the two systems is represented by the reduced volume of the substrate (and/or nutrient solution) available to each plant, and this justifies the particular management of the nutrient solution in the soil-less system. Also for this reason, one of the most relevant characteristics of the nutrient solutions is the ionic concentration of nutrients, which is usually much greater than that of the circulating solution of the soil, even though this is variable (Table 2).

In order to grow, plants do not require such high nutrient concentrations as those required for soil-less cultivation reported in Table 2. Such high concentrations in soil-less cultivation are used to ensure a good nutrient reserve and to simplify the preparation, the control (e.g. of the electrical conductivity with a conductivity meter) and the rein- 
Table 1. Advantages and disadvantages of soil-less crops (modified from Resh, 2012).

\begin{tabular}{|c|c|}
\hline Advantages & Disadvantages \\
\hline Grow on poor soils. & High investment and energy costs. \\
\hline No need for soil sterilisation. & $\begin{array}{l}\text { Environmental problems (disposal of exhausted substrates such as rockwool, } \\
\text { losses in the soil of draining nutrient solution, use of huge amounts of plastics). }\end{array}$ \\
\hline $\begin{array}{l}\text { No risk of accumulation of phytochemical residues } \\
\text { (bromine residues, etc.), also in the groundwater. }\end{array}$ & Absence of suitable cultivars. \\
\hline No need for tillage, manuring, initial fertilisation. & No indications for the distribution of pesticides with the nutrient solution. \\
\hline $\begin{array}{l}\text { Elimination or reduction of risk of attack from } \\
\text { soil-borne pathogens. }\end{array}$ & No hydric, thermal, nutrient and biological flywheel of the substrate. \\
\hline No herbicide treatments. & Risk of epidemics. \\
\hline Rapid rotations no longer needed. & Occurrence of diseases normally absent in the soil. \\
\hline Greater water use efficiency. & Highly professional operator skills needed. \\
\hline Better use of fertilisers (efficient use of nutrients). & Dependence on electricity and other economic sectors. \\
\hline $\begin{array}{l}\text { Increase in yields (better plant health, greater plant density, } \\
\text { more productive longevity). }\end{array}$ & Continuous monitoring. \\
\hline \multicolumn{2}{|l|}{ Greater uniformity and earliness. } \\
\hline Better overall production quality. & -2 \\
\hline $\begin{array}{l}\text { More efficient greenhouse management (rapid succession, } \\
\text { high greenhouse efficiency, vertical exploitation). }\end{array}$ & \\
\hline
\end{tabular}

tegration of the nutrient solution.

The composition of the nutrient solution reflects the chemical composition of the cultivated plant rather than that of the circulating solution of the soil. Under these conditions, the plants require less energy to actively remove nutrients. Moreover, the nutrient solutions are generally more concentrated than the circulating solution of the soil because smaller concentrations could cause a situation of deficit, especially in the case of infrequent renewal of the nutrient solution (Epstein, 1972). However, the removal ratios between nutrients and water vary widely in response to different climatic conditions, even on the same day. For this reason, they usually suggest nutrient concentrations higher than those provided by the removal ratio between nutrients and water in order to ensure sufficient availability of all nutrients.

Moreover, it should not be forgotten that the solutions of the soil are better buffered by reactions of ion exchange, absorption-deabsorption, dissociation and precipitation, as well as by the cycle of nutrients and mineralisation of organic matter. The absence of a similar buffering capacity in systems of soil-less culture requires the use of high concentrations of nutrients. Finally, the nutrient solutions are very often easily prepared with four or five salts to meet the needs of the macroelements; this reduces the possibility of obtaining wider ratios among the concentrations of the elements.

\section{The substrate}

Substrates are defined as all those materials, used alone or mixed appropriately, that can provide the root system with better conditions (in terms of one or more aspects of plant growth) than those offered by agricultural soil (Noto, 1993). In soil-less crops, the substrate replaces the soil because the natural soil is often poorly suited to cultivation due to chemical (reaction, nutrient availability, etc.), physical (density, structure, water retention, etc.), or biological (presence of pathogens, exhaustion, etc.) limitations, or because in this way it controls plant growth better. Plants grown in pots are characterised by a particularly
Table 2. Concentration ranges of macronutrients $(\mathrm{mM})$ in soil and soil-less crops (reworked by Epstein, 1972; Nielsen, 1984; Marschner, 1996).

\begin{tabular}{|c|c|c|}
\hline Nutrient & Soil & Soil-less \\
\hline $\mathrm{N}-\mathrm{NO}_{3-}$ & 0.5 -10 (usually <1-2) & $5-20$ \\
\hline $\mathrm{N}-\mathrm{NH}_{4}+$ & $0.02-0.05$ & $0.5-2$ \\
\hline $\mathrm{P}\left(\mathrm{H}_{2} \mathrm{PO}_{4^{-}}\right)$ & $0.005-0.05$ & $0.5-2$ \\
\hline $\mathrm{K}+$ & $0.2-2$ & $5-10$ \\
\hline $\mathrm{Ca}^{2}+$ & $0.5-4$ & $3-6$ \\
\hline $\operatorname{Mg} 2+$ & $0.2-2$ & $1-2$ \\
\hline $\mathrm{S}\left(\mathrm{SO}_{4}{ }^{2-}\right)$ & $0.1-2$ & $1.5-4$ \\
\hline
\end{tabular}

high (and unbalanced) ratio between the aerial part and root, and by much bigger water, air and nutrient requirements than those that are recorded on the soil (and in the open field) where growth rates are slower and the volume of soil available for the roots is theoretically unlimited. To meet these requirements, we need to use substrates that, alone or in a mixture, ensure chemical, physical and biological conditions that are optimal and stable in time. To do this, different types of materials have long been traditionally used in horticulture and in the nursery industry. Over the last few decades there has been, on the one hand, a significant increase in the number of materials used, arising from industrial processes, to be used with or in replacement of traditional materials and, secondly, there has been a growing use of substrates of cultivation (Gruda, 2012).

The substrate must perform different functions: i) support the plant and provide air, water and nutrients to the roots; ii) it must not contain pathogens; and iii) should not be phytotoxic. Any organic or inorganic material can be used as a substrate, provided that it meets the above conditions. There is no universal substrate or mixture that is valid for all species and in all situations of cultivation. It is, therefore, appropriate to carefully select the individual materials according to the different conditions in which they will be used: the environment, species to 
be cultivated, cultivation phase (germination, rooting of cuttings, plant production, plant breeding) and system of cultivation.

Suitability of the material depends on a number of physical, chemical and biological characteristics. In each case, it must be always remembered that growth on substrate in a container (pot, bag, etc.) occurs in conditions of reduced thermal flywheel, limited water reserve, and possible waste of water and nutrients (pollution).

A good culture medium should be able to offer the plant the highest availability of water (i.e. have a good water retention capacity), but at the same time ensure sufficient aeration to the roots (Table 3). In other words, there should be a balanced ratio between the microporosity (constituted by pores able to retain the water at the end of the drainage after complete saturation) and the macroporosity (porosity free, provided by all the pores that do not retain water and that are filled with air). Better water:air ratios are ensured by materials with high porosity (optimally 75\%) and with the right balance between micro (40$60 \%)$ and macro (15-35\%) pores. With crops in small containers (e.g. quick pots), the total porosity is expected to reach $85 \%$ of the volume.

\section{Horticulture evolution}

Soil-less systems have revolutionised the horticulture nursery industry and techniques of installation, with significant benefits for nurserymen and farmers. Over the last few years, researchers and farmers have shown an increased interest in soil-less cultivation. Even if, in Italy, national horticulture is based on very simple management techniques, the use of high technological crop systems is attracting more attention, and is able to increase productivity and significantly reduce water and other resources, while cutting down the pollution caused by pesticides, fertilisers and plastics. Soil-less cultivation is probably the most important practice, especially for species in which radical diseases are difficult to control. In Italy, although the first studies on soilless cultivation were started in the 1960s and 1970s by Massantini, growers only really started showing interest in 1990 (40-50 ha). Ten years later, the surface area under soil-less cultivation had grown to 400 ha (Carruthers, 2002). In Italy today, soil-less cultivation affects approximately $5-7 \%$ of the surface area dedicated to horticultural crops in greenhouses, while in other countries, e.g. in the Netherlands and in Spain (Almeria), they represent the main cultivation system used.

There are three main reasons why the use of such a system is not more widespread in Italy: the lack of technical assistance, the small size of farms, and the inadequacy of the greenhouse systems that host the soil-less cultivation (Incrocci et al., 2009).

In general, soil-less crops are more convenient than ordinary crops when it is necessary to operate in difficult pedoclimatic conditions or in the presence of very valuable species that are difficult to cultivate, or during the multiplication and reproduction phase. For ornamental crops and cut flowers, soil-less cultivation in a protected environment ensures a more constant and higher quality production, and favours production planning, the latter being of fundamental importance in this sector.

The Italian flower nursery is characterised by a highly varied production. A very clear example is the cultivation of acidophilic plants in the district of Lago Maggiore and in the Biella area. The birth of the Typical Flowers of Lago Maggiore brand in the 1980s shows how, in time, camellias, azaleas and rhododendrons have forged deep links with the territory in which they are grown and with local tradition. This has been thanks to their aesthetic value, to their location in sites of historical interest, and to their importance in landscape gardening/their relevance to the local landscape. They were initially grown in the soil, but extraordinary weather events and the growth in demand, without the limitations of normal periods of production and the biological cycles of the open field, have led to more advanced cultivation techniques being developed. The adoption of the greenhouse and soil-less crops has resulted in products with excellent quality standards that meet the needs of consumers and are competitive with producers from across the Alps. Nowadays, the productive specialisation of floricultural companies has led to European market recognition of the well-established typical production of Lago Maggiore and the Biella area. Here, producers have achieved their market position through the refinement of production techniques that now need to be improved to accommodate the demands of their leading customers, and the general orientation of consumers and of the European Union towards more natural products.

Peat is the major component of the substrates used for growing plants in pots. Recently, a number of environmental issues have been raised about its use because its extraction depletes peatlands, a habitat with special ecological value. Peat resources are also being depleted and the renewal process takes a very long time. In countries in southern Europe, such as Italy, peat is imported, with an impact both in environmental and in economic terms. The use of more readily available resources, also in terms of reuse/recycling of waste materials from local productive sectors, could represent a valid response to the needs of the nurserymen to reduce the use of peat substrates in floriculture while increasing the environmental sustainability of soil-less cultivation. In Italy, there is a real opportunity to use readily available materials with a view to reuse waste materials from other production chains, as confirmed by recent studies. For example, rice husk and hazelnut shells were found to be suitable alternatives to peat for the cultivation of Camellia japonica (Berruti and Scariot, 2013; Larcher and Scariot, 2009; Larcher et al., 2011; Figure 1), and coconut fibre showed positive effects also in the cultivation of other acidophilic species, such as

Table 3. Example of subdivision (\%) between the phases of a soil and a substrate.

\begin{tabular}{lcc} 
Phase of the medium & Soil & Substrate \\
Solid & 50 & 25 \\
Liquid & $25(35)$ & 50 \\
\hline Gaseous & $25(15)$ & 25 \\
\hline
\end{tabular}

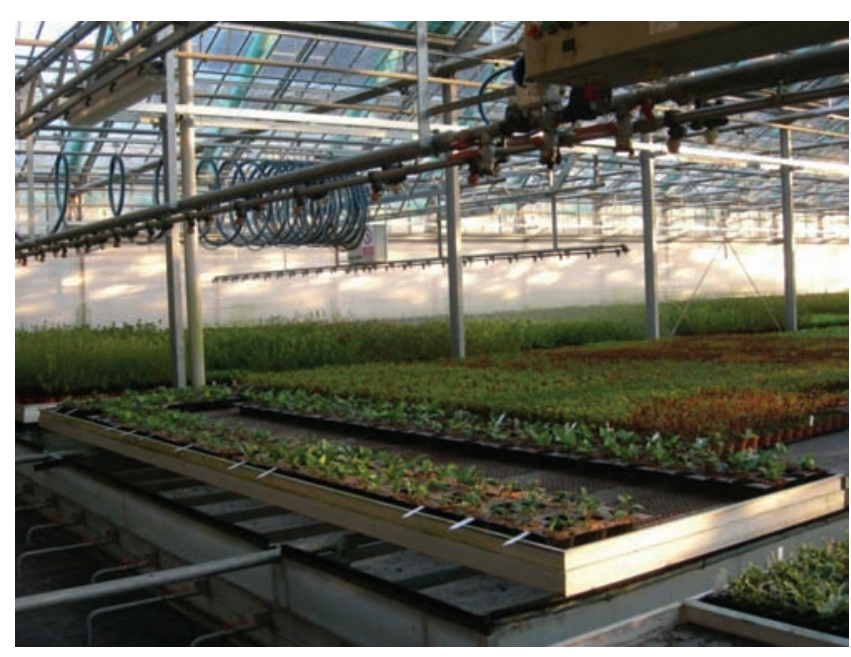

Figure 1. Pallet with cuttings of Camellia japonica after planting in quick pots. 
Table 4. Soil-less table grape phenology during two crop cycles.

\begin{tabular}{|c|c|c|c|c|c|}
\hline Crop cycle & Cycle start & Bud break & Flowering & Veraison & Harvest \\
\hline \multicolumn{6}{|c|}{ Cv Black Magic } \\
\hline I & 5 January & 12 February & 5 April & 10 May & 21 June \\
\hline II & 9 July & 15 July & 10 August & 16 September & 16 October \\
\hline & Cycle start & Bud break & Flowering & Veraison & Harvest \\
\hline \multicolumn{6}{|c|}{ Cv Vittoria } \\
\hline I & 5 January & 14 February & 10 April & 10 May & 21 June \\
\hline II & 9 July & 18 July & 14 August & 12 September & 16 October \\
\hline
\end{tabular}

Table 5. Yield of soil-less table grape ( $t / h a)$ during two reproductive cycles.

\begin{tabular}{|c|c|c|c|c|}
\hline \multirow[b]{2}{*}{ Cultivars } & \multicolumn{2}{|c|}{ Refrigerated stored vines } & \multicolumn{2}{|c|}{ Productive vines during I cycle } \\
\hline & Vittoria & Black Magic & Vittoria & Black Magic \\
\hline I cycle & 39 & 45.2 & 39 & 45 \\
\hline II cycle & 23 & 29.6 & 39 & 21.8 \\
\hline Combined total & 62 & 74.9 & 78 & 67.1 \\
\hline
\end{tabular}

Rhododendron japonicum, Leuchotoe axillaris and Pieris japonica (Berruti and Scariot, 2012), while the compost based on Posidonia beached residues has been successfully used for the production of tomato, pepper and lettuce seedlings (Mininni et al., 2012; Mininni et al., 2013). In parallel with the development of new substrates, we need to widen our knowledge of cultivar management (Caser et al., 2010; Scariot and Gullino, 2010) in order to adapt irrigation and plant protection treatment requirements (Berruti and Scariot, 2013). In order to increase the sustainability of soil-less crops, one extremely interesting possibility would be to reduce the contribution of fertilisers and pesticides in crops by applying inocula of arbuscular mycorrhizal fungi selected ad hoc (Berruti and Scariot, 2011).

In recent years, there has been a growing interest in soil-less cultivation in fruit growing in relation to the capabilities inherent in these systems to make production processes more dynamic.

In arboriculture, in the nursery, soil-less cultivation techniques are used to produce propagation material that reduces the production time of plants destined to be transplanted in the field, and, at least experimentally, to produce fig tree (Ficus carica L.) and table grape (Vitis vinifera L.) (Figure 2).

Melgarejo et al. (2007) reported the possibility of soil-less cultivation increasing fig production up to 18-fold compared with that obtained in the ground, saving water (up to 90\%), fertilisers, and pesticides, and with lower plant management costs. Di Lorenzo and Mafrica (2000) and Di Lorenzo et al. $(2009,2012)$ have shown that, in soil-less table grape cultivation, it is possible to produce more than 40 tons per hectare, and in southeastern Sicily, two production cycles can be achieved in the same year, the first in the period from January to June and the second from July to October (Table 4). Having two production cycles in the same year and in the same greenhouse with the varieties Black Magic and Vittoria has resulted in a total combined production from the two cycles of over 60 and 70 tons, respectively, depending on whether the second cycle used the same plants as the first or plants refrigerated between March and June (Table 5). However, studies on soil-less cultivation have also been considered in apricot, peach and cherry trees. Soil-less vine cultivation has been proposed by producers in suitable areas but with serious problems of soil-borne pathogens. Production of soil-less table grape has numerous advantages (Table 6), although critical issues are still the subject of research: i) adaptability
Table 6. The main advantages of soil-less table grape cultivation (reworked by Di Lorenzo et al., 2009, 2012; Buttaro and Santamaria, 2010).

1) Production of table grapes on soils infested by soil-borne pathogens

2) No graft requirement

3) Multiple cropping cycles in a year

4) Marketing oriented production

5) Increase in yield per unit area

6) Anticipate and/or delay ripening and harvesting

7) Reduce pesticide treatments and labour requirement

8) Improve product quality

9) Increase efficiency of input

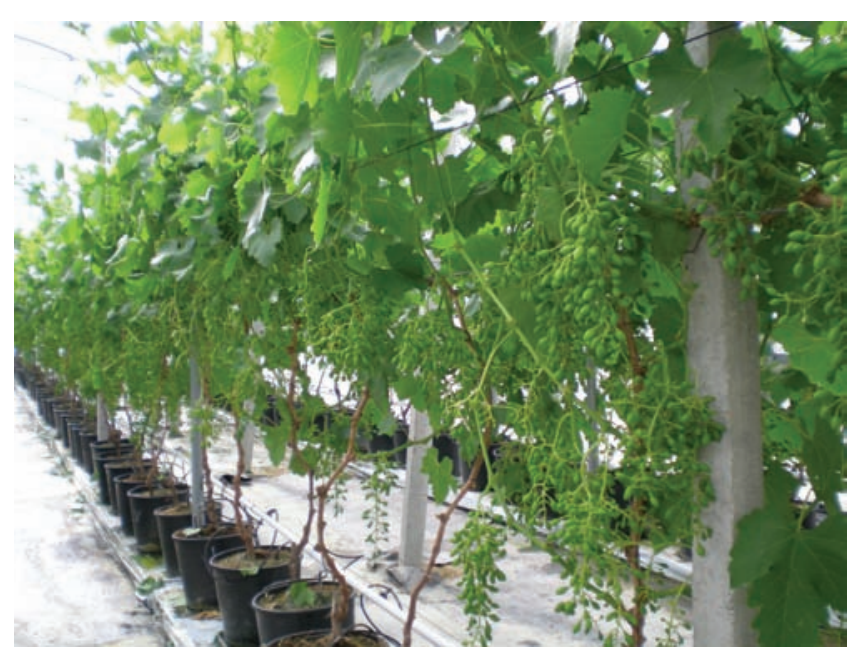

Figure 2. Soil-less cultivation of table grape (cultivar Vittoria). 
to the technique of the different cultivars; ii) composition of the nutrient solution; iii) cultivation cycles to be carried out during a different period from the traditional one.

Soil-less vine cultivation for table grape is very quick and flexible. The first year of growth takes place in the greenhouse and then outdoors to satisfy plant chilling requirements. After just one year, the second year (in greenhouses) produces clusters of very good size with little millerandage and no traces of pesticide (the confined cultivation environment minimises the need to intervene with phytosanitary products). The cycle consists of two phases: i) training the plant, i.e. rooting cuttings and growing the shoot in the first year; ii) production (second year). Cuttings are rooted in the greenhouse from February to April. Small pots (approx. 0.4 L) filled with peat are used (Figure 3); when the rooting has occurred, cuttings are placed in larger pots (volume approx. $10 \mathrm{~L}$ ) filled with cultivation substrate (e.g. a mixture of perlite and peat) and then transferred outside. The plants are grown with a single shoot that will form the cane during the production phase. In the second year (the production phase), before budburst, the plants are transferred to the greenhouse. For cultivation, ordinary canopy management practices are applied (summer pruning, tying buds, leaf removal and cluster selection) (Buttaro et al., 2012).

The estimates of the costs and benefits of adopting the soil-less technique to cultivate table grape will be crucial to its diffusion. However, consideration should also be given to the very high cost (up to 30,000 euros/ha) of planting a traditional vineyard in which deep soil tillage must be carried out, involving ploughing and, where the soil is mainly composed of rock, subsequent grinding.

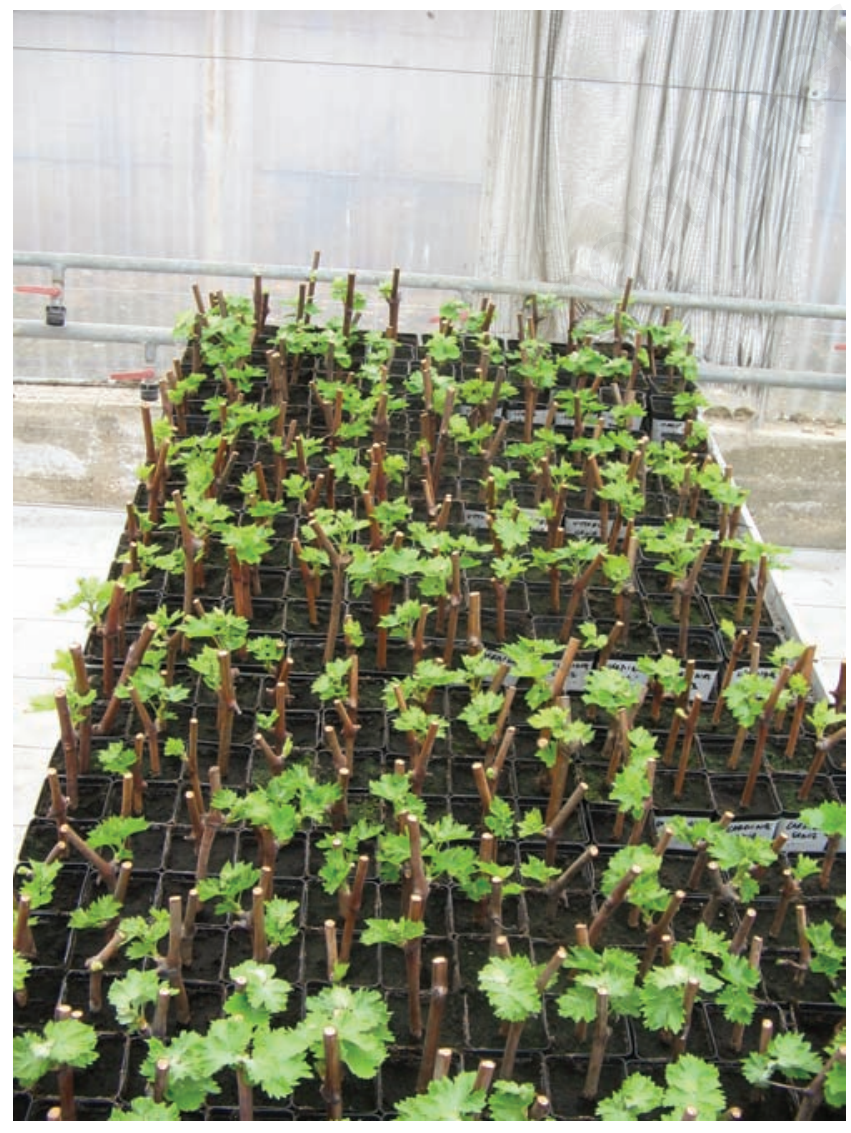

Figure 3. Rooting vine cuttings in the greenhouse.

\section{Quality and typicity}

Soil-less cultivation systems allow total quality levels to be achieved, i.e. improvement in the quality of both the product and the productive process (Santamaria and Valenzano, 2001).

The spread of soil-less crops has raised questions in the scientific community and doubts and confusion among members of the public in relation to the changes in the qualitative profile of the products. These changes are most likely a result of the specific characteristics of the production methods used. The qualitative profile of the products obtained by methods of soil-less cultivation appears to be substantially the same as that of the corresponding products coming from crops grown under traditional methods (Gruda, 2009; Santamaria and Valenzano, 2001). Any differences seem to be in favour of the soil-less methods, especially for the parameters relating to the nutritional, organoleptic and hygienic-sanitary characteristics (Gruda, 2009; Santamaria and Valenzano, 2001).

Some aspects of the quality of vegetables produced under soil-less cultivation have clearly been improved, such as a decrease in phytosanitary residues, enhanced organoleptic characteristics, and longer shelf life (Cefola et al., 2011). Special dietary requirements are also sometimes satisfied, e.g. enrichment of and/or increase in content of selenium (Pedrero et al., 2006), iron (Inoue et al., 2000), and omega 3 (Palaniswamy et al., 2000), and lower nitrate content (Santamaria et al., 2001). However, soil-less cropping systems are agricultural systems that are under the strong influence of Man and are increasingly conditioned by this, and this influence weakens the links with the production areas and then to the territory. As a result, products grown under these systems remain unrelated to marketing strategies that link food consumption to the valorisation of typical, organic and natural products.

This is particularly true in Italy, where crops from soil-less cultivation are not included among protected geographical indication (PGI) food products. In general, soil cultivation is a crucial element that characterises the protected designation of origin, and if crops are not produced in this way then recognition of the product is lost. An example of exclusion of soil-less crops from the production specification is the Pachino tomatoes PGI.

\section{References}

Berruti A, Scariot V, 2011. Selection of arbuscular mycorrhizal fungal isolates for sustainable floriculture. Acta Hortic. 917:319-24.

Berruti A, Scariot V, 2012. Coconut fiber: a peat-like substrate for acidophilic plant cultivation. Acta Hortic. 952:629-35.

Berruti A, Scariot V, 2013. Efficacy of flurprimidol and peat alternatives on growth control of potted camellias. N. Zeal. J. Crop Hortic. Sci.[In press].

Buttaro D, Santamaria P, 2010. Uva da tavola senza suolo, una prospettiva interessante. Inf. Agrario 66:60-1.

Buttaro D, Serio F, Santamaria P, 2012. Soilless greenhouse production of table grape under Mediterranean conditions. J. Food Agric. Environ. 10:641-5.

Carruthers S, 2002. Hydroponics as an agricultural production system. Pract. Hydrop. Greenh. 63:55-65.

Caser M, Torello Marinoni D, Scariot V, 2010. Microsatellite-based genetic relationships in the genus Camellia: potential for improving cultivars. Genome 53:384-99.

Cefola M, Pace B, Buttaro D, Santamaria P, Serio F, 2011. Postharvest evaluation of soilless-grown table grape during storage in modified atmosphere. J. Sci. Food Agric. 91:2153-9. 
Di Lorenzo R, Dimauro B, Guarasci F, Rinoldo C, Gambino C, 2012. Multiple productive cycles in the same year in soilless tablegrape cultivation. p 20 in Proc. 35th Word Congr. Vine and Wine, Izmir, Turkey.

Di Lorenzo R, Gambino C, Dimauro B, 2009. La coltivazione dell'uva da tavola in fuori suolo: stato attuale e prospettive. Bull. OIV 82:935-7.

Di Lorenzo R, Mafrica R, 2000. La coltivazione fuori suolo dell'uva da tavola - Risultati di un biennio di esperienze condotte in Sicilia. Riv. Frutticolt. Orticolt. 62:48-52.

Epstein E, 1972. Mineral nutrition of plants: principles and perspectives. Wiley, Weinheim, Germany.

Gruda N, 2009. Do soilless culture systems have an influence on product quality of vegetables? J. Appl. Bot. Food Qual. 82:141-7.

Gruda N, 2012. Sustainable peat alternative growing media. Acta Hortic. 927:973-9.

Incrocci L, Diara C, Pardossi A, Cavenago Bignami G, 2009. Strategie su cui puntare per affermare il fuori suolo. Inf. Agrario 65:43-5.

Inoue K, Kondo S, Adachi A, Yokota H, 2000. Production of iron enriched vegetables: effect of feeding time on the rate of increase in foliar iron content and foliar injury. J. Hort. Sci. Biotechn. 75:209-13.

La Malfa G, 1996. La qualità degli ortaggi nella coltivazione fuori suolo. Tecn. Agric. 48:35-46.

Larcher F, Berruti A, Gullino P, Scariot V, 2011. Reducing peat and growth regulator input in camellia pot cultivation. Hort. Sci. 38:3542.

Larcher F, Scariot V, 2009. Assessment of partial peat substitutes for the production of Camellia japonica. Hort. Sci. 44:312-6.

Marschner H, 1996. Mineral nutrition of higher plants. Academic Press, London, UK.

Melgarejo P, Martìnez JJ, Hernàndez F, Salazar DM, Martìnez R, 2007.
Preliminary results on fig soil-less culture. Sci. Hortic. 111:255-9.

Mininni C, Bustamante MA, Medina E, Montesano F, Paredes C, PérezEspinosa A, Moral R, Santamaria P, 2013. Evaluation of posidonia seaweed-based compost as a substrate for melon and tomato seedling production. J. Hortic. Sci. Biotech. 88:345-51.

Mininni C, Santamaria P, Abdelrahman HM, Cocozza C, Miano T, Montesano F, Parente A, 2012. Posidonia-based compost as a peat substitute for lettuce transplant production. Hort. Sci. 47:1438-44.

Nielsen NE, 1984. Crop production in re-circulating nutrient solution according to the principle of regeneration. pp 421-446 in Proc. 6th Int. Congr. Soilless Culture (ISOSC), Lunteren, The Netherlands.

Noto G, 1993. I substrati di coltivazione. Tecn. Agric. 45:3-39.

Palaniswamy UR, McAvoy RJ, Bible BB, 2000. Omega-3-fatty acid concentration in Portulaca oleracea is altered by nitrogen source in hydroponic solution. J. Amer. Sci. Hort. Sci. 125:190-4.

Pedrero Z, Madrid Y, Camaraj C, 2006. Selenium species bioaccessibility in enriched radish (Raphanus sativus): a potential dietary source of selenium. Agric. Food Chem. 54:2412-7.

Resh HM, 2012. Hydroponic food production: a definitive guidebook for the advanced home gardener and the commercial hydroponic grower, 7th ed. CRC Press, Boca Raton, FL, USA.

Santamaria P, Elia A, Gonnella M, Parente A, Serio F, 2001. Ways of reducing rocket salad nitrate content. Acta Hortic. 548:529-37.

Santamaria P, Valenzano V, 2001. La qualità degli ortaggi allevati senza suolo. Italus Hortus 8:31-8.

Scariot V, Gullino P, 2010. Evaluation of flowering time and ornamental characteristics in Autumn Camellias. Acta Hortic. 885:319-24.

Winsor GW, Schwarz M, 1990. Soilless culture for horticulture crop production. FAO Plant Production and Protection Paper, Publication No. 101, Rome, Italy. 